\title{
Energy Efficient Short Term Spectrum Auction Using the Concept of Green Payments
}

\author{
Abdulkarim Oloyede ${ }^{1} \cdot$ David Grace $^{1}$
}

Published online: 27 April 2016

(C) The Author(s) 2016. This article is published with open access at Springerlink.com

\begin{abstract}
This work seeks to demonstrate the economic importance of short-term spectrum auction and how it can be implemented with fewer overheads. This can be achieved using the proposed market driven sealed bid spectrum auction process with a novel concept called the green payment. The green payment serves as an incentive during the auction process to encourage the users to use the radio spectrum in an efficient manner. The model proposes to tax users that are not power efficient while those that are power efficient pay a subsidy during the auction process. First, the appropriate bidding and auction periods are examined and determined such that the bidding period is dependent on the traffic load in the system. Using the obtained bidding period, the value of the green payments is then examined and the appropriate level of tax and subsidy are also determined. The economic importance of the model in terms of the revenue generation for the service provider and in terms of the tax being adequate to finance the subsidy is also examined. These results show that using the proposed concept of green payment, the energy consumed and the system delay can be reduced when compared to a non-green payment based auction process. The results also show that the proposed model is beneficial to the service provider in terms of increase in profit and that the tax and subsidy system is self-sustaining.
\end{abstract}

Keywords Green payments - Dynamic spectrum access - Dynamic spectrum auction · Bidding period · Energy efficiency

\section{Introduction}

Mobile devices using the wireless spectrum access are fast becoming a major element that we rely upon daily in order to access a wide range of digital services and applications. However, this is being threatened by spectrum scarcity. This is as a result of the present static spectrum

Abdulkarim Oloyede

aao500@york.ac.uk

1 Communications and Signal Processing Research Group, University of York, York, UK 
allocation and the fixed pricing mechanism that is presently adopted leading to congestion on the radio spectrum $[1,2]$. The static spectrum allocation does not allow for the same spectrum band to be shared among different service providers while users are usually locked into a long-term contract. Generally, with most mobile phone contracts, the users are paying a fixed amount monthly for unlimited access to the radio spectrum. Therefore, static pricing scheme discourages users from using the radio spectrum in an efficient manner because the scheme provides no incentive to users to turn off unused applications, especially those applications running in the background that are not needed. However, dynamic spectrum access (DSA) has recently been recognised as an approach to sharing of the radio spectrum [3]. In addition to DSA, spectrum auction is also proposed as a fair means of allocating the radio spectrum dynamically [3-5]. Therefore, the goal of this paper is to examine and propose a practical framework for secondary access to the radio spectrum by using a market driving short-term spectrum auction process. However, unlike traditional auction process, this paper does not intend to use only the user's financial power in allocating the radio spectrum. This is because the transmit power of one user has an effect on the other users using the same frequency band in close proximity. Hence, in short-term, the DSA auction process with spectrum reuse and the amount of spectrum that is available for auction can be influenced based on the transmit power of the users in the system. Therefore, an incentive-based auction with a reserve price which also depends on the transmit power of the users is proposed. The use of an incentive has been described in [6] as an essential element in the success of a DSA scheme. The use of an incentive-based auction to include a reserve price also has some other advantages: when the spectrum is congested, the radio spectrum can be allocated in an efficient manner and during off-peak periods; a fair level of revenue can also be maintained. Generating more revenue from the radio spectrum is important because according to Fig. 1, the present revenue obtained from the use of the radio spectrum is not proportionate to the increase in demand for the radio spectrum.

To this end, this paper considers the use of two groups of users referred to as the low powered users (LPU) and the high powered users (HPU) in order to show the heterogeneous nature of the future wireless network. The presence of a spectrum broker who is responsible for carrying out the auction process is also assumed. Any user seeking access to the radio spectrum submits a sealed offered price, which is the user's valuation (bid) for the radio spectrum. Based on the received requests and received signal to noise ratio (SNR) of the users requesting the spectrum at a particular time, the spectrum broker applies the green payment to the received bid by subsidising the power efficient users and by applying

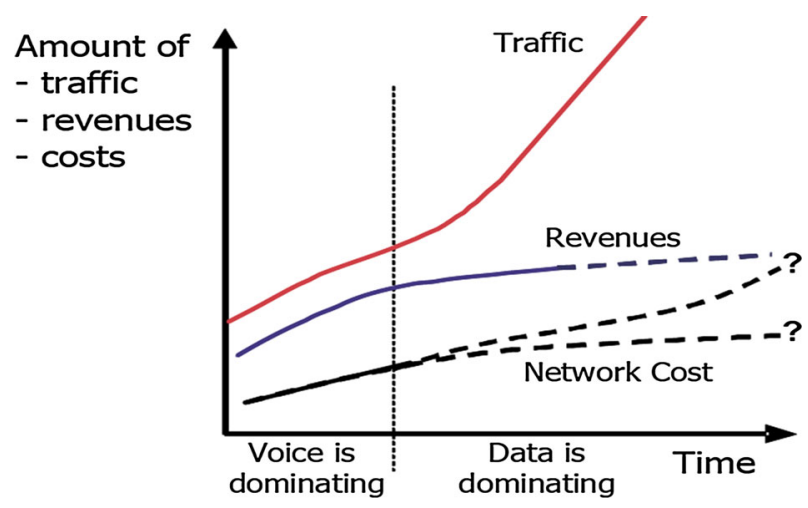

Fig. 1 Traffic and revenue for increasing data (Source [7]) 
a tax to the bids of the users who are not power efficient. After the application of the green payment, the users with the highest set of bids are offered the available channels.

In a similar work, a short-term knapsack-based spectrum auction using the concept of the coordinated access band was proposed [8]. The scheme allows the service provider to maximise the revenue generated. Sequential and concurrent auction mechanism were also considered in [9] while considering the revenue obtained by the wireless service provider (WSP). However, the paper uses the concurrent auction in combination with the first price spectrum auction. A slot by slot spectrum auction was proposed in [6] using price discrimination scheme in order to maximise both the revenue of the WSP and that of the primary spectrum owner. This paper is different from other papers because it does not only consider the revenue obtained by the service provider but also considers how the auction process affects the performance of the system in terms of delay and the energy consumed. Another main difference is that it offers an incentive to the users to use the spectrum in an efficient manner unlike in [10] where the incentive was offered to the primary users in order to compensate for the interference experienced as a result of secondary access to the radio spectrum.

The rest of this paper is organised as follows. Section 2 describes the system model by explaining and defining all the components in the proposed model. The problem formulation with the general system setup would be described in Sect. 3. Section 4 shows the results and the discussions of the results while the conclusions are provided in Sect. 5.

\section{System Model}

An uplink infrastructure network is considered consisting of the users, the spectrum broker and the database. The elements in the network are as described in Fig. 2. The users in the system are divided into two equal groups in order to show the heterogeneous nature of the

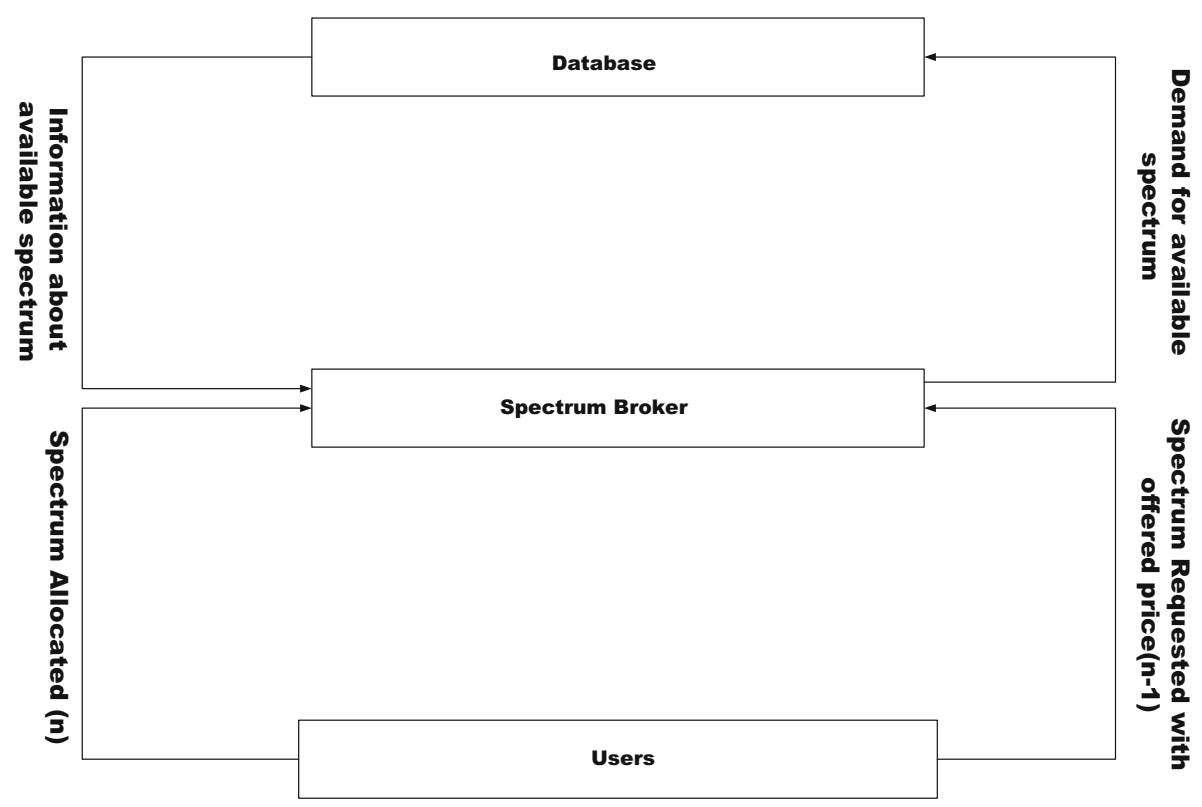

Fig. 2 The database approach to spectrum auction 
system. This is necessary because, with the introduction of DSA, different types of users are seeking access to the same portion of the radio spectrum using varying levels of transmitting power depending on the requirements. However, this is limited to two groups: low powered users (LPU) and the high powered users (HPU) for simplicity's sake. Throughout this paper, an HPU is always an HPU and this is also true for a LPU. We do not consider the scenario where the user can move from one group to the other.

The system consists of $N$ users and $N_{\mathrm{TC}}$ transmission channels in each cell. During an auction period $(t)$, the number of users seeking access to the radio spectrum are time varying. They are represented as $N_{\mathrm{USA}}$. After the auction process, a number of winners emerge. These winners are represented as $N_{\mathrm{WU}}$. A channel for transmission can only be utilised by one user at a time and users cannot communicate directly to another user except via the central entity (base station). During any auction period, the database provides the information to the auctioneer regarding the available channels in each cell before the auction process. The number of available channel in each cell as provided by the database is represented as $N_{\mathrm{AC}}$. After the auction process, the winning users are allocated a channel, but not all winning user that is allocated a channel is able to transmit successfully because of inference or noise from adjacent users sharing same channel. This is explained in more detail in Sect. 3. $N_{\mathrm{UT}}$ is used to represents the number of users who are able to transmit after the auction and the allocation process and for the reason stated earlier $N_{\mathrm{UT}} \leq N_{\mathrm{WU}}$.

\subsection{The Bidding Price (BP)}

The bidding price is the amount submitted by a user to the auctioneer as its valuation for the use of the radio spectrum. The proposed model assumes that all the users are truthful and submit a true valuation. Such valuation reflects the user's private value to access the radio spectrum. These assumptions were made because the issue with truthful bidding and bid shading which dominates auction theory in the perspective of an economist is more of an economic problem than an engineering problem. Hence, it is not considered in this paper. Truthful bidding allows the bidders to bid their true valuation [11] while bid shading is a situation where some bidders lower their valuations in order to get some added advantage during the auction process [12]. The users in this paper value the radio spectrum in a similar way to that widely used in auction theory based models. The valuation of the users show their willingness to pay and it is drawn from a range of values represented as $\left[V_{\max } V_{\min }\right]$. This is formulated based on the conventional settings in economics where users has private valuation has done in [13]. Each bidding user independently draws their bid value with a probability density function expressed as:

$$
f_{V}\left(v_{i}\right)=\frac{1}{V_{\max }(i)-V_{\min }(i)}
$$

where $V_{\max }$ and $V_{\min }$ are the maximum and the minimum possible bid valuation a user can have respectively in price unit. The valuation $\left(V_{i}\right)$ depends on the user's budget per file and it is always less than the users maximum budget and it $\left(V_{i}\right)$ is derived from Eq. 1 . The budget for all the users in the system is the same and it is as specified in the parameters Table 1 and throughout this paper, a situation where the bidding user does not have enough to cover the necessary payments is not considered. Each of the bidders generates a bid using the distribution which can be expressed as:

$$
b_{i}(\text { Price Unit })=\frac{\left(N_{\mathrm{USA}}-N_{\mathrm{AC}}\right) V_{i}}{\mathrm{~N}_{\mathrm{AC}}}+V_{\min } \quad \text { For } i=1,2 \ldots N_{\mathrm{USA}} \text { and } N_{\mathrm{USA}}>N_{\mathrm{AC}}
$$


The above equation was formulated to reflect the conventional economic theory of demand and supply because with an essential commodity like the radio spectrum, demand and supply plays an important role in determining its economic value. The conventional theory of demand and supply can be found in [14]. It is also assumed that all the users have knowledge of $N_{\mathrm{AC}}$ and $N_{\mathrm{USA}}$ while formulating Eq. 2. This assumption is quite strong but reasonable, since it enables the understanding of how an auction process can be implemented for short-term spectrum access.

Using Eq. 2, each of the users intending to transmit generates a bid within the given range and submits the same to the auctioneer. This must be done within a given time window known as the bidding period $(t)$. The appropriate bidding period is determined later in this paper.

\subsection{Auction Process}

The auction model adopted in this work is the simultaneous sealed bid auction where no bidder knows the bid of any other user and in the same auction period, no user can amend the offered price after putting in the bid. The simultaneous process is adopted in order not to introduce additional delay into the system. For an auction process to take place, the value of the $N_{\mathrm{USA}}$ is always greater than the $N_{\mathrm{AC}}$. Hence this is taken into account when formulating the auction period later in this work. During the auction process, the amount paid by any of the winning bidders depends on bids submitted by the users and the payment rules put in place by the auctioneer. In order to assess the effect of the payment rule on the auctioneer's revenue, two types of payment rules are examined: The discriminatory

Table 1 Parameters used

\begin{tabular}{ll}
\hline Parameters & Value \\
\hline Cell radius & $2 \mathrm{~km}$ \\
Interference threshold & $-40 \mathrm{dBm}$ \\
$S N I R_{\text {treshold }}$ for HPU & $1.8 \mathrm{~dB}$ \\
$S N I R_{\text {treshold }}$ for LPU & $21 \mathrm{~dB}$ \\
Users in a cell & 200 \\
Number of cell & 19 \\
{$\left[b_{\text {min }} b_{\text {max }}\right]$} & {$[58]$} \\
Desired percentile & 30 \\
$T h r_{\text {max }}$ & $4.5 \mathrm{bps} / \mathrm{Hz}$ \\
$\alpha$ & 0.65 \\
$S N I R_{\text {max }}$ & $21 \mathrm{~dB}$ \\
$S N I R_{\text {treshold }}$ & $1.8 \mathrm{~dB}$ \\
$C r$ & 0.5 \\
File size & $2 \mathrm{Gbits}$ \\
Frequency reuse factor & 3 \\
Height of base station & $15 \mathrm{~m}$ \\
Budget & $100,000 \mathrm{price}$ units \\
Transmit power for LPU & $0.09 \mathrm{~W} / \mathrm{bit}$ \\
Transmit power for HPU & $0.9 \mathrm{~W} / \mathrm{bit}$ \\
$N$ & $100(50 \mathrm{LPU}$ and $50 \mathrm{HPU})$ \\
\hline &
\end{tabular}


payment rule and the uniform payment rule. In the former method, all the winning users during the same transmitting period pay whatever value they bid while in the latter all the users in the same group transmitting in the same bidding period $(t)$ pay the same amount, which is usually the average price for all $N_{\mathrm{WU}}$ in the same auction period.

\subsection{The Reserve Price}

The reserve price $(r)$ is the minimum price paid before the spectrum is allocated. It is introduced because the demand for the radio spectrum is both time and space dependent and therefore, when the demand is low, the reserve price helps to retain the minimum selling price of the service provider. The reserve price might also prevent the use of the spectrum if the value is set too high. Therefore, the reserve price is formulated by taking into account the current traffic load in the system, the frequency band in use, the total number of channels in the system and the number of channels in use. The reserve price is expressed as:

$$
r(\text { Price Unit })=C_{f} N_{\mathrm{TC}} C_{r}
$$

where $C_{r}$ is a constant in price units, which is used to specify the value of a spectrum band in use. In this paper, this value is determined from the common knowledge regarding the common price of the radio spectrum and it is specified in the parameters table. This is introduced because the value of the spectrum varies depending on the frequency and the application that requires the use of the spectrum. Furthermore, users believe that the bigger the size of the network, the better the quality of service offered hence, the total number of channels in the system is also taken into consideration when calculating the reserve price. Consequently, the reserve price increases as the size of the network. The congestion factor $\left(C_{f}\right)$ is introduced because of the laws of demand and supply. The lower the demand the lesser the price and the higher the demand the higher the price of a commodity as explained in [15]. The congestion factor $\left(C_{f}\right)$ is the number of requesting users per channel during an auction period, which can be expressed as:

$$
C_{f}=\frac{N_{\mathrm{USA}}}{N_{\mathrm{AC}}}
$$

In this work, $C_{f}$ is the same for all the users who want to transmit within the same bidding period $(t)$.

\subsection{The Bidding/Auction Period $(t)$ and the Transmitting Period (T)}

An auction period $(t)$ represents the time window in which users that require the use of the radio spectrum submit their bids to the auctioneer. Only bids submitted within this time frame are considered by the auctioneer and only such users are considered as the contenders for the next available transmit channel slots. The value of $N_{\text {USA }}$ that submit a bid during an auction period depends on the user's arrival process. It is important to determine the appropriate auction period because a long bidding period allows more bidders to arrive and submit their bids, but this can introduce additional delay into the system and a short bidding period might not allow enough users to arrive for an auction to be carried out. This is because if $N_{\mathrm{USA}}<N_{\mathrm{AC}}$ then there is no need for an auction to be carried out since all users seeking access can be allocated a channel. Another implication of more users arriving as seen from Eq. (2) is that the bids of the users depend on the value of $N_{\mathrm{USA}}$, while $N_{\mathrm{USA}}$ 
depends on the bidding period $(t)$ as explained. Therefore, the higher the number of arrivals $\left(N_{\text {USA }}\right)$, the higher the bids submitted by the users. This might be considered as a positive implication because the revenue obtained by the WSP is dependent on the user's bid. The higher the bidding values, the higher the revenue of the auctioneer. The number of arriving bidders also determines the reserve price set by the auctioneer as seen from Eq. (4). Therefore, in the modelling scenario it can be concluded that the longer the bidding period, the longer the delay introduced into the system and the shorter the bidding period, the smaller the value of the revenue obtained by the WSP. Hence, the bidding period is an important factor that needs to be examined and chosen appropriately in order to balance the trade-off between the auctioneer's revenue and the delay in the system.

The appropriate bidding period is obtained such that the number of bidding users arriving is more than the number of channels. The number of bidders that are able to transmit after the allocation of the radio spectrum is defined as $N_{\mathrm{UT}}$. $N_{\mathrm{UT}}$ is less than or equal to $N_{\mathrm{WU}}$ or $N_{\mathrm{AC}}$. It is less than $N_{\mathrm{WU}}$ if some of the winning users are not able to transmit after being allocated the spectrum because their bids are below the reserve price or they do not meet the transmission requirement such as the SNIR threshold. $N_{\mathrm{UT}}$ is less than $N_{\text {AC }}$ when some of the available channels are not in use usually as a result of users offering a bid price which is below the reserve price. Furthermore, it is also assumed that each of the users has only one file to send at any giving time hence, the number of files arriving is the same as the $N_{U S A}$. This assumption is reasonable because before each file is sent an auction must take place. The modelling assumptions can be summarised as:

$$
\begin{gathered}
N_{\mathrm{WU}}=N_{\mathrm{AC}} \\
N_{\mathrm{UT}} \leq N_{\mathrm{AC}} \text { or } N_{\mathrm{WU}}
\end{gathered}
$$

Usually, the application using wireless radio spectrum are time/delay sensitive. This sensitivity varies from one application to the other. Voice communication is more delay sensitive than data communication. However both has an acceptable delay/time limits. In order not to breach this time limit, we need to define an appropriate auction period that would satisfy the users requirement. The appropriate auction period should allow for $N_{\text {USA }}$ to be greater than $N_{\mathrm{AC}}$ and such bidding period should not introduce additional or significant delay into the system. Hence, we derive the appropriate auction period. First, an expression for the probability of $N_{U S A}$ in any auction period is defined using a Bernoulli distribution to model the independent time interval between the user's arrivals. The bidding period is assumed to be $t$ and the probability $\left(P_{r}\right)$ of a user arrival in each trial as shown in Eq. 7. The bidding period $t$ is divided into smaller periods called the trial periods. If no user arrives during a trial period, it is termed as a failure but a user arrival during this trail period is known as a success, which can be expressed as:

$$
P_{r}=\frac{\lambda t}{N_{t r}}
$$

where $\lambda$ is the average user arrival rate and $N_{\text {tr }}$ is the number of trials in period $t$. The number of failed attempts (failure) is $N_{\text {tr }}-N_{\text {USA }}$. The probability of $N_{\text {USA }}$ users arriving in $N_{\text {tr }}$ trials is given by the binomial distribution expressed as [16]:

$$
P_{r}\left(N_{\mathrm{USA}} \text { out of } N_{t r}\right)=\frac{\mathrm{N}_{\mathrm{tr}} !}{N_{\mathrm{USA}} !\left(N_{\mathrm{tr}}-N_{\mathrm{USA}} !\right)} p^{N_{\mathrm{USA}}}(1-p)^{N_{\mathrm{tr}}-N_{\mathrm{USA}}}
$$


Substituting (7) into (8):

$$
\left(N_{\mathrm{USA}}\right)=\frac{N_{\mathrm{tr}} !}{N_{\mathrm{USA}} !\left(N_{\mathrm{tr}}-N_{\mathrm{USA}} !\right)} \frac{\lambda t^{N_{\mathrm{USA}}}}{N_{\mathrm{tr}}}\left(1-\frac{\lambda t}{N_{\mathrm{tr}}}\right)^{N_{\mathrm{tr}}-N_{\mathrm{USA}}}
$$

Assuming the probability of a user arrival is small, the probability of $N_{\text {USA }}$ users arriving in $N_{t r}$ trials is given by the binomial distribution can be written as:

$$
\left(1-\frac{\lambda t}{N_{\mathrm{tr}}}\right)^{N_{t r}} \cong e^{-\lambda t}
$$

Therefore, the standard expression for the Poisson distribution is obtained as follows:

$$
P_{r}\left(N_{\mathrm{USA}} \text { users arriving in } t\right)=\frac{e^{-\lambda t}(\lambda t)^{N_{\mathrm{USA}}}}{N_{\mathrm{USA}} !}
$$

The above expression (11) shows that the probability depends on the arrival rate and therefore, the equation represents the most likely number of bids to be received in any auction period $t$. User's arrival is used interchangeably with file arrival because it is assumed that each of the users only has one file to send at a given time. This bidding period must allow an auction to take place; therefore $N_{U S A}$ must be greater than $N_{\mathrm{AC}}\left(N_{\mathrm{USA}}>N_{\mathrm{AC}}\right) . N_{\mathrm{AC}}$ is assumed to be fixed in this section. Furthermore, an expression to allow at least $N_{\mathrm{AC}}+1$ bids to be submitted in an auction period is derived. This is because if the number of bids received is less than the number of available channels, there is no need for an auction to be carried out. Therefore, substituting $\lambda=\frac{T_{L}}{T}$ into Eq. (11) and varying the period, where $T_{L}$ is the traffic load in the system in Erlang and $T$ is the holding time also known as the transmitting period.

In order to illustrate how we derive the parameters used in our model an example is provided using Fig. 3 under the assumption that $N_{\mathrm{AC}}$ is 4 hence for an auction process to be carried out the number arrivals must be $>4$. Hence, a user arrival of 5 is used in this example and we assume a date rate of $3.8 \mathrm{bps} / \mathrm{Hz}$ for this illustration. From Fig. 3, it can be concluded that the appropriate bidding period that allows exactly 5 arrivals $\left(N_{\mathrm{AC}}+1\right)$ decreases with the traffic load in the system when examined for all traffic loads. This is

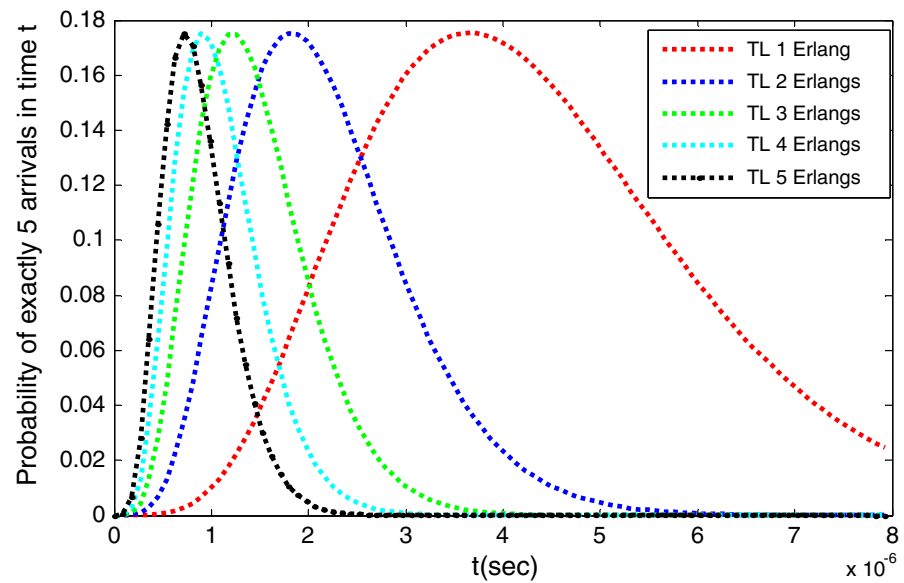

Fig. 3 Probability of at exactly 5 arrivals in time $t$ 
because the probability of arrivals depends on the traffic load in the system. Furthermore, because the auction process takes time depending on the traffic load in the system, a scenario where the auction process and transmission process are carried out simultaneously is modelled.

In order to understand the approach used in this paper, an example is provided using Fig. 4, where 5 users are arriving out of the $N$ possible users in the system during each bidding period. The bidding price $(B P)$ and 3 bidding periods $\left(t_{1}\right.$ to $\left.t_{3}\right)$ are illustrated with this example. For proper understanding just for this example the users are represented as $N_{i}^{a}$, where the subscript $i$ represents the user number and superscript $a$ represent the packet number. Hence $N_{1}^{2}$ means that user number one is about to send packet number two. 3 channels are also assumed to be available in each bidding period (in our modelling process, the number of available channel varies and the information regarding the available channel is provided by the database). The reserve price (RP) is assumed to be 4 in this case and it is placed below the bidding period because the auctioneer is not aware of this value before the auction process. In the first bidding period, users number 1 to 5 arrive into the system and each with a bidding value as indicated in the Fig. 4, since 3 channels are available, the auctioneer picks the 3 users with the highest biding values $\left(N_{1}, N_{5}\right.$ and $\left.N_{4}\right)$. However only $N_{1}$ and $N_{5}$ are allowed to transmit because of the reserve price. All the users that are not successful in a bidding period retries in the next bidding period. Hence it can be seen from the example that users 2 to 4 are also bidding again in $t_{2}$. This is in addition to user 6 and 1 . User 6 is a new bidder who is attempting to send the first file as seen from the superscript $\left(N_{6}^{1}\right)$ but user 1 is attempting to send the second file after the initial success in the first bidding and transmission period.

\subsection{The Auctioneers Revenue}

The expected revenue $\left(R_{e}\right)$ of the auctioneer from one bidder during a single auction period can be expressed as:

$$
R_{e}(\text { Price Unit })=b_{i}
$$

Substituting Eq. (4) into Eq. (12), the expected revenue can be expressed as:

$$
R_{e}(\text { Price Unit })=\frac{\left(N_{\mathrm{USA}}-N_{\mathrm{AC}}\right) V_{i}}{N_{\mathrm{AC}}}+V_{\min }
$$

The total revenue obtained by the auctioneer during all the auction periods $\left(t_{n}\right)$ can be represented as:

$$
R_{e_{\text {total }}}(\text { Price Unit })=\sum_{1}^{t_{n}} \sum_{1}^{N_{\mathrm{UT}}} R_{e}
$$

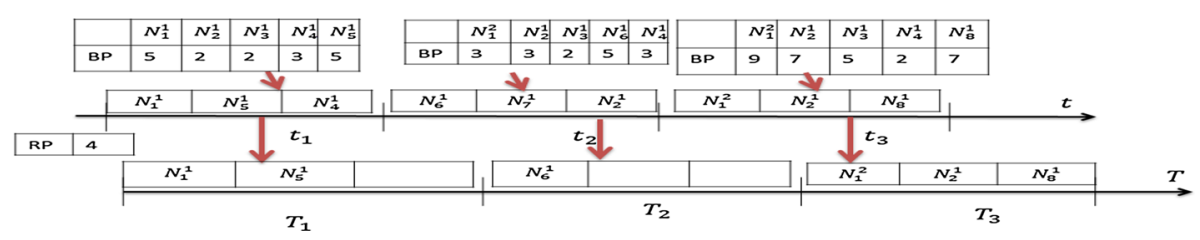

Fig. 4 The bidding process 
It can be seen from the Eq. (13) that as $N_{U S A}$ increases the expected revenue also increases. The number of arriving users $\left(N_{\mathrm{USA}}\right)$ can only increase provided the bidding period is increasing. Therefore, the bidding period has a direct relationship with the revenue of the WSP. This also shows that the bidding period is an important factor that needs to be considered carefully when using an auction to allocate the spectrum. Another important factor that is considered throughout this paper is the energy consumed.

\subsection{The Energy Model}

According to Feeney and Nilsson [17], the energy consumed by wireless devices consists of the energy used in generating and processing the signals. It also includes the energy consumed by the power amplifiers and other components. The energy model used in this paper can be represented as a 2 state Markov chain as shown in Fig. 5. In the energy model a user can transit from 1 to 4 as shown below:

1. A user who has file(s) to send moves into the OFF state and continues to be in this state until such a user is among the winning bidders.

2. A user who is among the winning bidders moves from the OFF state to the ON state.

3. The user remains in the $\mathrm{ON}$ state until after transmission, if the transmission is successful, or until when the user receives a failed signal, either because of low offered bid compared to the reserve price or because of a poor quality channel.

4. After transmission, the user moves back to the OFF state in order to send the next file.

In the $\mathrm{ON}$ state, it is assumed that a transmission is successful provided the signal to noise plus interference ratio (SNIR) and the reserve price are above the set thresholds. If the user moves from the ON state to the OFF state, and the thresholds are not met, then the energy consumed in processing the request of the user during the state transition is considered as energy wasted. A processing time, which is the time taken to process the received bid, is also assumed. All users that move from the ON state to the OFF state have the same processing time.

As mentioned earlier the device can require a high transmit power or a low transmit power when in the ON mode. The transmit power for each group of users is fixed but both groups can switch to the OFF mode. Generally, in this paper, the HPU transmits at higher bit rate compared with the LPU depending on the users SNIR based on the truncated Shannon bound. Therefore, the energy consumption is modelled as a function of the bit rate which is directly proportional to the transmit power level. The energy consumed in transmitting one file by user $i$ is as shown below:

$$
E_{i}(\text { Joules })=\frac{P_{i} S_{f}}{B_{r}}+P_{D} t_{d}
$$

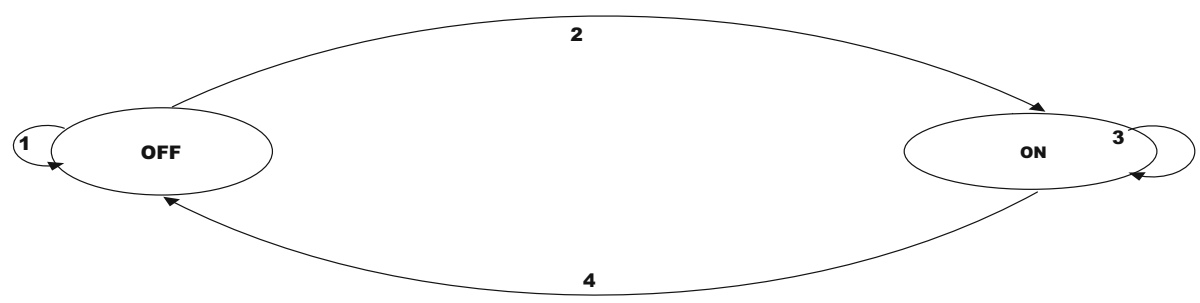

Fig. 5 Energy and system model as a two-state Markov chain 
where $P_{w}$ is the transmit power for user $i$ in watts, $S_{f}$ is the file size in bits and $B_{r}$ is the bit rate in bits/seconds, $P_{D}$ is the power used in powering the user device in Watts and $t_{d}$ is the time in seconds in which the device is powered on. The device is assumed to be powered on during the bidding and the transmission periods. It is assumed that all users are transmitting the same file size. Therefore, a higher bit rate means transmitting for a shorter period for the HPU compared to the LPU. The total energy $\left(E_{T}\right)$ consumed by the system in Joules can be expressed as:

$$
E_{T}(\text { Joules })=\sum_{i=1}^{N_{W U}} E_{i} N_{F G_{i} i}
$$

where $N_{\mathrm{FG}_{i}}$ is the total number of file generated for user $i$ (both successfully sent and the ones not successful sent) and $N$ is the total number of users in the system. The average energy consumption per file sent is calculated as shown below. Where $N_{\mathrm{FS}_{i}}$ is the total number of files successfully sent by user $(i)$ in the system.

$$
E=\frac{E_{T}}{\sum_{i=1}^{N} N_{\mathrm{FS}_{i}}}
$$

\subsection{The Green Payment (R)}

The green payment $(R)$ is either in the form of a tax or a subsidy and the main aim of introducing the green payments is to allow the bids of the LPU to be subsidised, the bids of the HPU to be taxed and to increase the probability of LPU winning the bid. This is because all the users (LPU and the HPU) are all opportunistic spectrum users and such users need to reduce the interference to other users by keeping their transmit power level low. Hence, the aim is to use the green payment to encourage the users to keep their interference level as low as possible. This is because this paper wants the primary users (they are not considered in this paper) to perceive the interference at a level, which does not disturb their transmissions. The auction-modelling scheme allows the granting of access to the radio spectrum to the HPU only when the bid of the HPU after the tax is above the reserve price and above the bids of the LPU with the subsidy. This is because sometimes due to the value of money involved; low demand for the use of the spectrum or the importance of the application seeking the use, the HPU should be allowed to transmit after paying the price for using such transmits power. An equation of the green payment is (Eq. 19) derived from the inverse of the Truncated Shannon Bound (TSB) is obtained to either tax or subsidise the users [18]. The TSB represents the transmission rates that can be achieved in practice given an adaptive modulation scheme in a real world scenario. This is dependent on the SNIR of the user expressed as

$$
\begin{gathered}
T h r= \begin{cases}0 & S N I R<S N I R_{\text {threshold }} \\
\alpha . S(S N I R) & S N I R_{\text {threshold }}<S N I R<S N I R_{\max } \\
T h r_{\max } & S N I R>S N I R_{\max }\end{cases} \\
\quad S(S N I R)=\log _{2}(1+S N I R)
\end{gathered}
$$

where $S(S N I R)$ is the Shannon bound and $\alpha$ is the rate reduction factor as defined in the parameters table, $T h r_{\max }$ is the maximum throughput for the codeset and $T h r$ is the throughput of the system. $T h r_{\max }$ and $S N I R_{\text {threshold }}$ are specified in the parameter table. The 
$S N I R_{\text {threshold }}$ is the minimum threshold that allows the detection of the information at the receiver and $S N I R_{\max }$ is the maximum SNIR beyond which there is no change in throughput. The TSB is used to represent the transmission rates that can be achieved in practice given an adaptive modulation scheme in a real world scenario. This is dependent on the SNIR of the user. In order to use the green payments to control the interference caused by the users requiring high SNIR in a fair manner, and to penalise or subsidise users based on the interference they contribute into the system, an equation related to the TSB is used to derive the green payment equation. The reason for using this equation is due to the fact that the transmission rate is an important parameter in a wireless communication system. This is because the transmission rate is dependent on the SNIR and this is dependent on transmit power and interference. The derived green payments equation formulated from the TSB is written as:

$$
\mathrm{R}(\text { Price Unit })= \begin{cases}2^{1+\beta \theta}-1 & \text { For green payment subsidy } \\ 2^{1+\beta \theta}+1 & \text { For green payment tax }\end{cases}
$$

where $\beta s$ the green payment factor derived later in this paper. The value of $\beta$ is chosen in such a way that the green payments does not introduce too much tax/subsidy into the system leading to delay or reduction in the system throughput, hence the reason for it being called the green payment factor. $\theta$ is the absolute value of the linear difference between the SNR value of a user $i\left(\psi_{i}\right.$ and the value of the SNR of a set threshold $\left(\psi_{j}\right)$.

$$
\theta_{i}=\psi_{i}-\psi_{j} \mid \text { for } i=1,2,4 \ldots N_{\mathrm{USA}}
$$

The set threshold $\left(\psi_{j}\right)$ is derived by first arranging the received SNR of the $N_{U S A}$ users who are seeking access to the radio spectrum at time $t$ in an ascending order

$$
\psi_{t}=\left[\psi_{1}, \psi_{2}, \psi_{3} \ldots \psi_{N_{\mathrm{USA}}}\right]
$$

Then to determine which of the SNR at time $t$ is the set threshold, the equation below is used, where $P_{c}$ is the desired percentile. The appropriate value of the desired percentile is obtained later in this paper. A percentile is usually used in statistics to indicate what percentage of scores is less than set threshold in an investigation.

$$
|j|=\left\lfloor\frac{P_{c} N_{\mathrm{USA}}}{100}+\frac{1}{2}\right\rfloor
$$

The above equation gives an absolute value (integer) known as the percentile rank. This shows that whatever the value of $j$, the $j$ th SNR in Eq. (21) is the set threshold $\left(\psi_{j}\right)$. For example if $j$ is 2, then the second SNR $\left(\psi_{2}\right)$ in Eq. 21 is the set threshold, therefore $\psi_{j}=\psi_{2}$ with this example. The set threshold is not the same or related to the SNIR threshold $\left(S N I R_{\text {threshold }}\right)$ in the TSB equation. The value of the percentile rank used has an effect on the total revenue needed to subsidise the bids of the users as seen from Eq. (22). As $P_{c}$ increases the percentile ranks also increases. This means that the number of users falling below the percentile rank increases and percentile value of 100 means that all the users are subsidised and no user is taxed. As explained earlier, the green payment equation can either be a tax or subsidy. In order to determine if the green payment of any user in the system is either a tax or subsidy, the scenarios that determines the users paying a tax or subsidy at any traffic load can is summarised into case 1 to 3 as explained below: 


\subsubsection{Case 1: Most of the $N_{U S A}$ Users Arriving in Period t are Low Powered Users}

This happens when all or most of the bids received in an auction period are from the LPU. When this scenario occurs some of the LPU whose SNR is above the percentile value appear to fall in the tax category. As an example when $N_{U S A}$ is 6 , and 4 transmit channels are available in the system. Where $\psi_{A}^{C}$ represents the SNR of all the users attempting to transmit at any period arranged in ascending order and superscript $C$ can either be LPU or HPU indicating low powered or high-powered users respectively and subscript $A$ represents the position number of each of the SNR values in ascending order. Therefore, in the above example, $A$ varies from 1-6 since there are 6 bidders seeking access to the radio spectrum during the auction period and the SNR is represented as:

$$
\psi_{A}^{C}=\left[\psi_{1}^{\mathrm{LPU}}, \psi_{2}^{\mathrm{LPU}}, \psi_{3}^{\mathrm{LPU}}, \psi_{4}^{\mathrm{LPU}}, \psi_{5}^{\mathrm{LPU}}, \psi_{6}^{\mathrm{HPU}}\right]
$$

Assuming the percentile rank $(J)$ which is calculated from Eq. (22) is 3 then $\psi_{j}^{c}=\psi_{3}^{\mathrm{LPU}}$. Therefore, $\psi_{4}^{\mathrm{LPU}}, \psi_{5}^{\mathrm{LPU}}, \psi_{6}^{\mathrm{HPU}}>\psi_{3}^{\mathrm{LPU}}$. This means that the SNR of users 4 and 5 who are LPU fall above the percentile value and the corresponding green payment for users 4 and 5 appear to be a tax. However, if this happens a tax is not be applied to the bid of the users (4 and 5 in the example) and neither is their bid subsidised, but users whose SNR are less than the value of percentile rank (users 1 and 2 in this example) are subsidised by adding the value of the green payment to their original bid and a tax is deducted from the bid of user 6 . This is done so that only the set of users with the lowest values of SNR are subsidised and this subsidy is only when necessary. In the above example, the HPU (user 6) has the least priority to transmit and user 4 is able to transmit if the bid is above the reserve price but the bidder is not subsidised.

\subsubsection{Case 2: Most of the Bidders Requiring the Use of the Spectrum are High Powered Users}

Some of the HPU have an SNR value less than the value of the percentile rank, using the same illustration as in the example above.

$$
\psi_{A}^{C}=\left[\psi_{1}^{\mathrm{LPU}}, \psi_{2}^{\mathrm{HPU}}, \psi_{3}^{\mathrm{HPU}}, \psi_{4}^{\mathrm{HPU}}, \psi_{5}^{\mathrm{HPU}}, \psi_{6}^{\mathrm{HPU}}\right]
$$

Assuming the percentile rank is 3, user 2 appears to fall into the category of users receiving subsidy, but in the work this set of users is not subsidised or taxed as the percentile rank that is used in this case is 2 rather than 3 . Therefore, user 3 is paying the minimum possible tax. This is done to prevent the bid of such user from going below the reserve price thereby making some of the available channels idle and lowering the system throughput.

\subsubsection{Case 3: The Arriving Bidders Fall Equally In-between the High Powered Users and Low Powered Users}

This is when the value of the percentile rank falls somewhere in between the HPU and the LPU: In this case each of the users is taxed or subsidised accordingly as illustrated below using the same illustration as previous examples:

$$
\psi_{A}^{C}=\left[\psi_{1}^{\mathrm{LPU}}, \psi_{2}^{\mathrm{LPU}}, \psi_{3}^{\mathrm{LPU}}, \psi_{4}^{\mathrm{HPU}}, \psi_{5}^{\mathrm{HPU}}, \psi_{6}^{\mathrm{HPU}}\right]
$$


Users 1 and 2 are subsidised and user 3 is neither taxed nor subsidised and the other users are taxed with user 4 paying the least amount of tax.

The aim of adopting the above rules is to subsidise users only when it is necessary, thereby preventing users from paying tax when the spectrum is not in use by the LPU. The rule also allows the tax received to be able to subsidise the bids of the LPU and prevent unnecessary denial of access to the HPU thereby, reducing the system throughput. As an example, substituting $N_{\mathrm{USA}}=5$ and $P_{c}=30$ into the Eq. (22) gives $j$ an approximate value of 2 meaning that in the event of at least 5 arrivals, 2 falls below the percentile rank. These two users should be able to transmit because their bids are either subsidised or they are paying the minimum amount of tax using the green payment equation. This also means that only two of the transmitting users are subsidised thereby helping in balancing the value of the tax and subsidy making the system self-sustaining.

The green payment $(R)$ as explained earlier is then applied to each of the received bids as:

$$
b_{i}^{\mathrm{final}}= \begin{cases}b_{i}+R_{i} & \text { For } \psi_{i}^{C}<\text { and } i \text { is a } \mathrm{LPU} \psi_{A}^{C}=\psi_{A}^{\mathrm{LPU}} \\ b_{i}-R_{i} & \text { For } \psi_{i}^{C}>\psi_{j}^{C} \text { and } i \text { is a HPU } \\ b_{i} & \text { For others }\end{cases}
$$

For $i=1,2,3 \ldots N_{\mathrm{USA}}$ and $j$ is the percentile rank of the threshold as where $b_{i}$ and $R_{i}$ are representing the bid submitted by user $i$ and the value of the green payments paid to user $i$ for a bidding period respectively.

\section{General System Setup}

One spectrum broker and $N$ wireless users are considered, modelling an infrastructure based uplink wireless network. The users require short-term access to the radio spectrum. It is assumed that the users in the same group transmit at the same constant power as shown in the parameters table. A hexagonal cell structure where cells that are located next to each other cannot share the same channel is assumed. A frequency reuse factor as specified in the table of parameters table. A fixed total number of channels $\left(N_{\mathrm{TC}}\right)$ is available in all the cells. The channels are assumed to have similar characteristics and in the absence of interference no channel is better in quality than the other. Hence, the users are allocated the least interfered channels based on their offered bid. The user with the highest bid is offered the least interfered channel and the winning bidder with the least bid is offered the most interfered channel. The file arrival process conforms to a Poisson distribution and the channel holding time is exponentially distributed. Each of the users who want to transmit during each auction period submits a uniform sealed bid $b_{i}\left(i=1,2,3, \ldots N_{\mathrm{USA}}\right)$ to the spectrum broker. A period $t$ allowing a minimum of $N_{\mathrm{AC}}+1$ arrival is assumed for the bidding period depending on the traffic load in the system as explained earlier using Fig. 3. The auction process is also carried out with multiple users $\left(N_{\mathrm{WU}}\right)$ emerging as winners depending on the number of available channels $\left(N_{\mathrm{WU}}\right)$ after applying the green payments to the bid of the users. The flow chart is shown in Fig. 6 below. The winning bidders are subsequently allocated to the available channels. Each user that is allocated a channel transmits successfully provided the SNIR of such user is above the SNIR threshold $\left(S N I R_{i} \geq S N I R_{\text {treshold }}\right)$ and the final bid price is above the reserve price $\left(b_{i}^{\text {final }} \geq r\right)$. Each of the users in each group transmits at a different bit rate according to the users received SNIR level, as determined by the TSB as explained in [7]. 


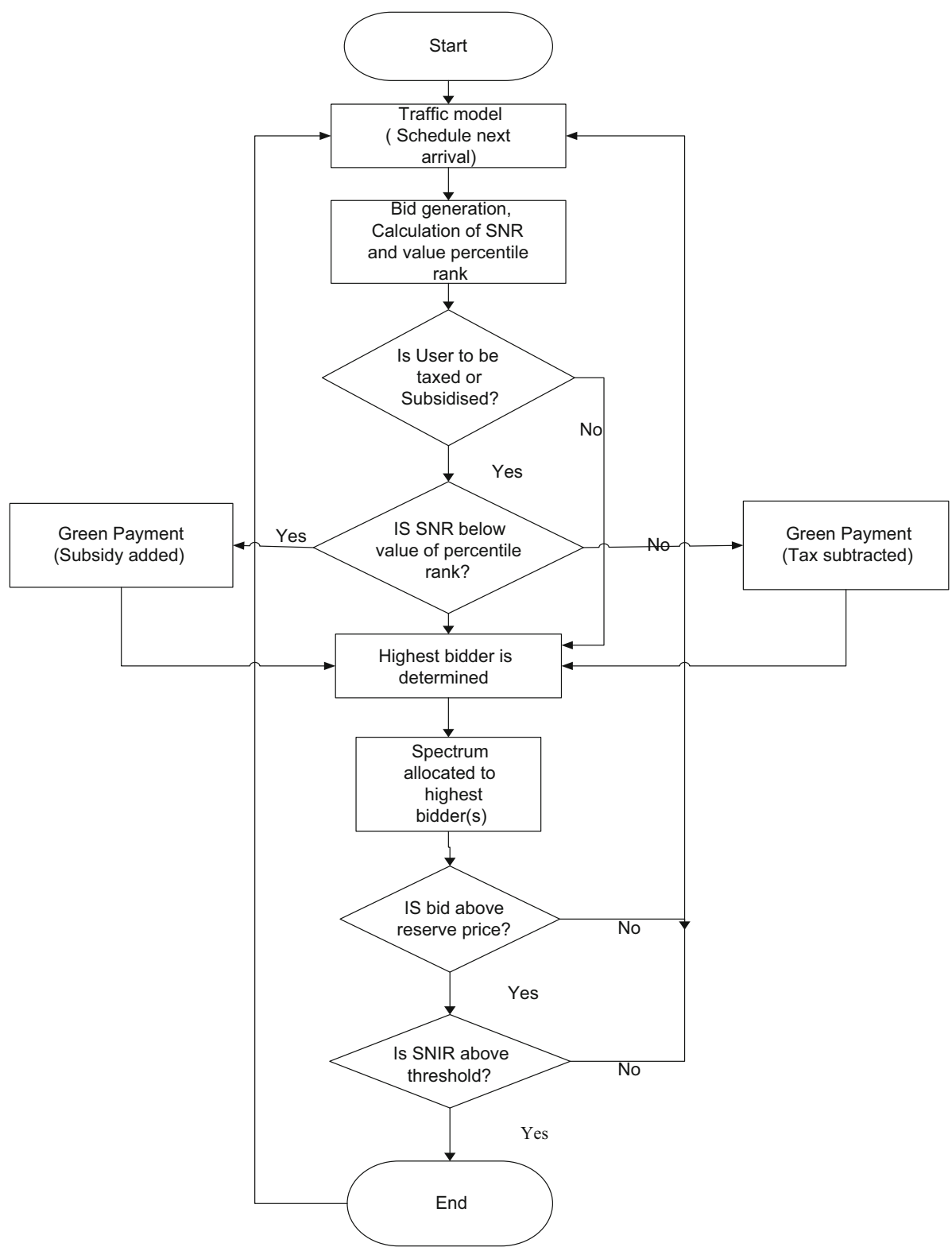

Fig. 6 System flow chart

\section{Results and Discussion}

The results in this paper are derived based on computer MATLAB modelling of an hexagonal cell structure using the parameters listed in Table 1 below with one spectrum broker and $N$ users in the system. The traffic arrival is based on Poisson distribution with arrival rate $(\lambda)$ and inter arrival rate described by an exponential distribution. The users are 
divided into two equal groups consisting of the HPU and the LPU. These two groups are used in order to mimic the heterogeneous nature of the future wireless network in a simplistic manner. The arrival process is independent of the user group as illustrated in cases 1 to 3 previously in sub section II (G). Hence in any bidding period $t$ the number of LPU or HPU arriving varies.

The first problem that is formulated is to determine the range of values for the green payments that maximise the system performance over different traffic loads. Such a value should make the system profitable and maximise the system capacity. It must also minimise the energy consumed by the cellular network. The value of the green payment factor (ß) in Eq. (19) is varied from 0 to 0.1 for different traffic loads to obtain a range of values for $\beta$ that achieves the aim of this paper. The aim is to allow the HPU to access the radio spectrum mainly when the LPU are not transmitting, to allow the tax obtained to pay for the subsidy, to reduce the amount of energy as a result of the auction process introduced into the system, not to introduce significant delay into the system and to allow the system to be able to operate at maximum capacity when required. It is worth pointing out that the system performance used in this work is per cell.

Furthermore from Eq. (21), it can be seen that as the percentile value increases, the percentile rank also increases, meaning that the number of users to be subsidised also increases as explained in the three modelling scenarios named case 1 to 3 in section II(G). Therefore in order to examine the effects of varying the green payment factor (ß) and the value of the percentile used on the value of the total green payment, the value of the green payment is varied. The total green payment $\left(R_{t o t}\right)$ is calculated as shown:

$$
R_{\text {tot }}(\text { Price unit })=R_{t t p}-R_{t s p}
$$

where $R_{t t p}$ and $R_{t s p}$ represents the total tax and total subsidy paid in price unit respectively.

Figure 7 shows the results obtained by varying the value of the green payment factor $(B)$ in Eq. (18) for different percentile values. It can be seen that with the percentile value of

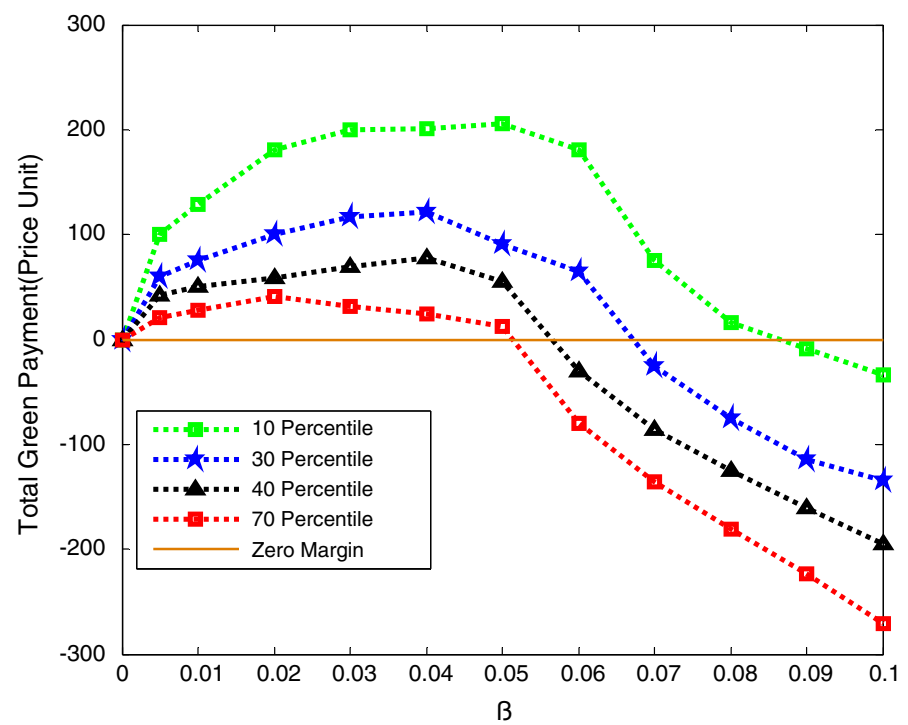

Fig. 7 Green payments against $\beta$ for different percentile value 
10, the value of the green payment factor can be increased up to 0.08 before the total green payment value goes below the zero margin. This is because the percentile equation as specified determines the number of users to be taxed or subsidised. This result is examined because the aim is to make the tax received to be able to pay for the subsidy. Therefore, the auctioneer does not have to set aside some amount to pay for the subsidy. It can be seen from this figure that as long as the value of $\beta$ is $<0.05$, then the system is self-sustaining for all the percentile value examined. As the percentile value increases the system can no longer be self-sustaining especially at high values of $B$, as the tax received cannot finance the subsidy. This does not pose a major problem if the subsidy is coming from an external source such as the government. However, in this work one of the aims is to allow the tax paid by HPU to be able to subsidise the LPU who are receiving a subsidy, hence the $30^{\text {th }}$ percentile is used in this paper. Furthermore, it can be seen that it is important to examine the range of values of $\beta$ that allows the system to be self-sustaining after having a fixed value of the percentile.

After selecting the 30th percentile based on the above reasons, the value is now kept constant to determine the range of values for $\beta$ that would make the tax pay for the subsidy. This is necessary because one of the aims of this paper is to allow the tax to pay for the subsidy. Figure 8 shows the green payment against the tax. The total green payments for all traffic loads are initially zero because no tax or subsidy is paid when $\beta$ is 0 . The total green payments rise after the initially zero value because as seen from Eqs. (19-22), the subsidy paid increases with increases in $\beta$ and also the tax increases with $\beta$. However as the value of $B$ increases, more HPU are squeezed out and the number of HPU paying a tax reduces in the process. Therefore, as the HPU are squeezed out gradually, the tax paid can no longer pay for the subsidy, thereby decreasing the value of the total green payment gradually until the total green payment goes to negative. The total green payment is negative when most or all the HPU in the system have been squeezed out. In terms of allowing the tax paid to pay for the subsidy and allowing the system to be self-sustainable the most suitable range of $B$ can be obtained to be between 0.01 and 0.05 for all the traffic loads examined

The aim of the green payment is not to completely squeeze out all the HPU in the system. Hence, the ratio of HPU to LPU during transmission is examined to determine the

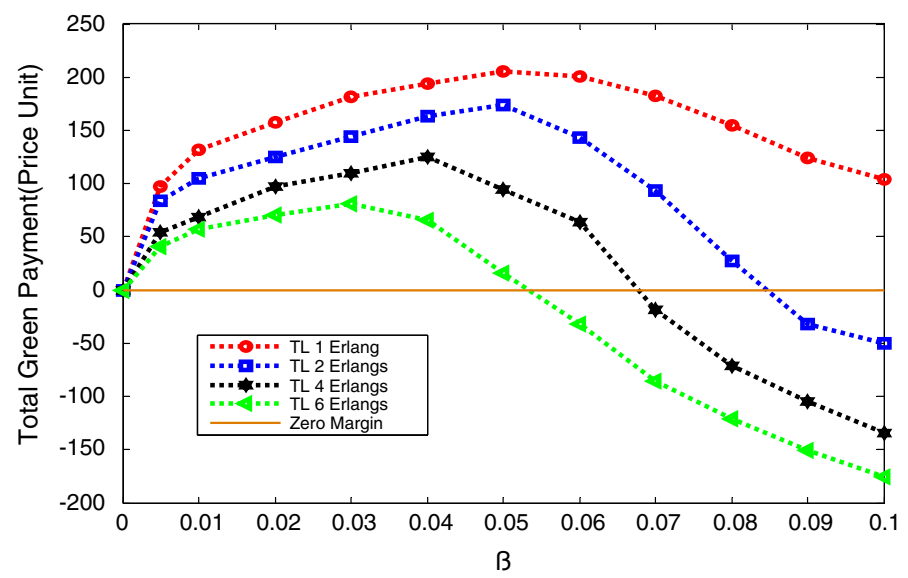

Fig. 8 The revenue from the green payment against $B$ 
value of $\beta$ that would not completely squeeze out all the HPU in the system depending on the traffic load in the system. It is important to show the ratio of the HPU to LPU in the system while varying $\beta$ because it helps to verify the fact that the reduction in the total green payment value is due to a reduction in the number of HPU in the system. As seen from Fig. 9, the ratio of the successful transmit files of the HPU compared to that of the LPU decreases as the value of $\beta$ increases from 0 to 0.1 for all the traffic loads examined. First, this result shows that there is a need to only test the range between 0 and 0.1 because as the value of $\beta$ approaches 0.1 the ratio decreases to zero. The decreasing ratio can especially be noticed at a traffic load above 2 Erlangs and it is as a result of the HPU being completely squeezed out due to the increase in the tax paid. As the tax increases, the bid of the HPU is subsequently below the reserve price. Therefore, a value of $\beta$ above 0.1 means the HPU are never granted access to the radio spectrum unless the overall budget is increased. This also means that no HPU are allowed access to the spectrum and there is no way of subsidising the bids of the LPU. It can be argued that if no HPU is granted access then there is no need to subsidise the LPU. However, the aim of this work is not to completely squeeze out the HPU but to grant the HPU access when the interference caused does not have a significant impact on the primary users in the system, or when LPU are not transmitting and the power can be spread over a wider bandwidth. It can be concluded from this that the higher the probability of LPU arriving, the lesser the chances the HPU are having of getting through. The result shows that the range of values for $\beta$ that allows a significant proportion of the HPU to transmit when the system is not in use by the LPU (if only the ratio is considered) is between 0 and 0.06 for all traffic loads between 1 and 6 Erlangs. Squeezing out the HPU and leaving the system empty or below its capacity is not an ideal situation because this gives a low value of throughput to the system. The system is operating below capacity because there are times when channels are available but because the offered bid of the HPU is below the reserve price as a result of the excess tax paid. Hence, there is a need to examine the throughput of the system with a varying value of $ß$. It is also important to examine the performance of the system as the value of $\beta$ is varied. This is because the performance of the system in terms of delay and throughput is important to any wireless system.

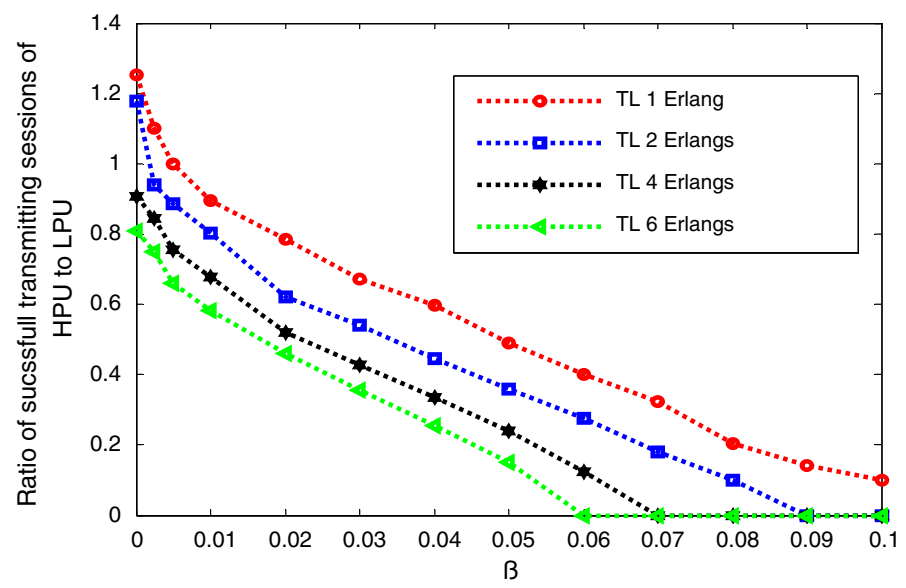

Fig. 9 Ratio of transmitting files of HPU to LPU against $\beta$ for different traffic loads 
Figure 10a shows the corresponding throughput value as $\beta$ increases from 0 to 0.1 when the least interference channel assignment scheme is used. It can be seen that at traffic loads of 1 and 2 Erlangs the throughput decreases at higher values of $B$. This is because the system is not loaded to capacity. This can also be because most of the HPU are completely denied access even when the LPU are not transmitting or because $N_{\mathrm{UT}}$ is less than $N_{\mathrm{AC}}$. Furthermore, at traffic loads of 4 and 6 Erlangs and at lower values of $\beta$, the throughput is lower because of the interference from the HPU transmitting. At lower traffic loads the LPU can avoid using the same channels as the HPU transmitting in other cells because of the least interfered channel assignment scheme in use. The avoidance is possible since more channels are available than the number of channels required. However, at higher traffic loads when the system is approaching maximum capacity, the least interfered channel assignment scheme has no effect. This is because the LPU has little or no option of transmission channels to choose from. This is because all the channels are busy most of the time due to the increase in the traffic load. In order to determine if it is the reserve price that is preventing the system from operating at full capacity below 4 Erlangs, the reserve price is removed. Figure 10b shows that removing the reserve price does not have any significant effect on the throughput at lower values of $\beta$, but it does increase the throughput at higher values of the green payment factor (ß) at traffic loads between 1 to 4 Erlangs. This signifies that at values of $\beta$ above 0.05 , there is a need to make the reserve price constant, especially at low traffic loads. Furthermore, the reserve price has no significant effect at higher traffic load above 4 Erlangs because the LPU who are getting subsidies are always transmitting on the radio spectrum and there is no need for the HPU to come into the system. From the throughput point of view, the range of values of the green payment factor that maximises the throughput is between 0.03 and 0.55 . This is because at this value the system can be operated to capacity.
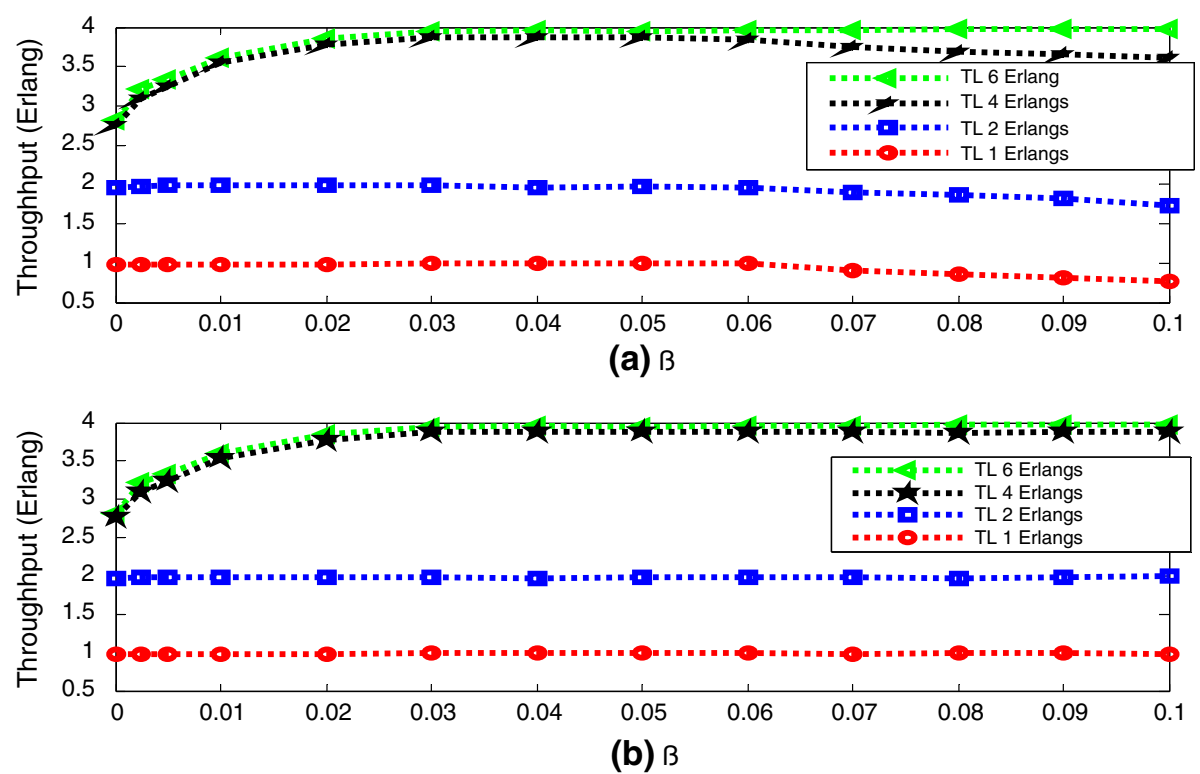

Fig. 10 Throughput against $\beta$ for different traffic loads for without and without reserve price 
After considering the throughput of the system, another important factor that is considered is the amount of energy consumed by the system. This is because one of the important features in many of the proposed future wireless systems is energy conservation. Figure 11 shows that the average energy consumed per successful file sent. The energy consumed here is the total energy consumed by only the users who are among the winning bidders $\left(N_{\mathrm{WU}}\right)$ and this is divided by the number of bidders who are able to transmit successfully $\left(N_{\mathrm{UT}}\right)$. It is worth pointing out that that the number of winning bidder $\left(N_{\mathrm{WU}}\right)$ is always less than or equal to the number of bidders who are able to transmit successfully after the transmission period $\left(N_{\mathrm{UT}}\right)$. The energy consumed reduces initially because the amount of energy consumed by the winning bidders reduces as the value of $\beta$ increases. This is because as $\beta$ increases more of the winning $\left(N_{\mathrm{WU}}\right)$ bidders are LPU as a result of the tax being paid by the HPU. However, as the value of $\beta$ increases the value of $N_{\mathrm{UT}}$ also reduces. This is because more of the HPU who are among the winning bidders are not able to transmit successfully. Initially, the reduction in the value of $N_{\mathrm{UT}}$ is gradual until it gets to a point where there are channels available but they are not put to use and all the users who are able to transmit successfully are only the LPU. This is because the HPU who are among the winning bidders are not always able to transmit. This is also because the value of the tax paid is higher as $B$ increases, thereby making the bid value of the HPU go below the reserve price. At the point when only the LPU are able to transmit, the average energy is flat as seen for values of $\beta$ above 0.06 . This is because on the average the number of HPU who are among the $N_{\mathrm{UT}}$ becomes constant and the traffic load is also constant. The rise in the value of the average energy consumed after a value of $\beta$ is equal to 0.05 is because there is a sudden reduction in the value of $N_{U T}$ without a corresponding reduction in the value of the energy consumed. The sudden reduction in the value of $N_{\mathrm{UT}}$ is because the HPU are almost completely squeezed out of the system at higher values of $B$. At high values of $\beta$ more of the winning bidders are LPU, but the number of LPU among the winning bidder is not enough to occupy all the available channels and the aim of the proposed model is not to make the system to work below its capacity. Therefore in terms of energy consumed by the system, the range of values of $\beta$ that significantly reduces the consumed energy per file has a range between 0.04 and 0.05 . This is because at those range

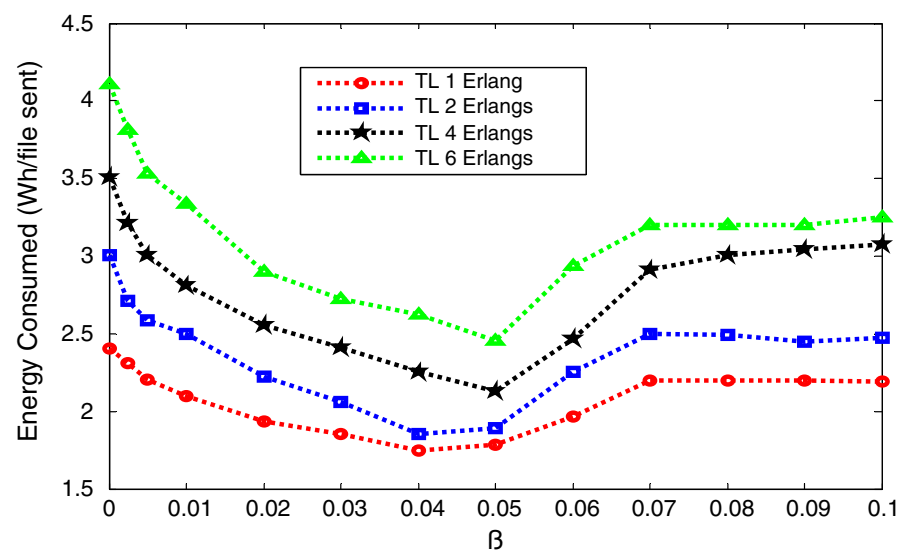

Fig. 11 Energy consumption against $\beta$ for different traffic loads 
of values, the average energy consumed per successful file sent is minimised for all traffic loads.

Taking all the above reasons into consideration $\beta$ is chosen to be 0.045 . This value is chosen in order to obtain an optimal value that maximises all the aims of this paper. This value is seen as the optimal value of $\beta$ because when the throughput and energy are taken into consideration, the optimal value is the point where the least energy is consumed. This value is also optimal because it makes the system to be self-sustainable (the tax received can pay for the subsidy paid out).

Using the optimal $\beta$ value of 0.045 , the system performance with and without the green payment and without the reserve price are examined in order to determine how each affects the general performance of the system. It is assumed that the bidders derive their bid using a uniform random distribution as explained earlier and a user does not pay if the data transmission is not successful but energy can still be consumed.

In order to determine the effects of using the discriminatory or uniform price increase, the two price increase scheme are examined alongside with the $50 \%$ and the random price increase. By random price increase it is meant that the user uses Eq. (4) during any bidding period to generate their bids all the time. However, with the $50 \%$ price increase the bidders such as bidder $(i)$ uses Eq. (4) to generate their new bid at time $t$ represented as $b_{i}^{t}$ but also add $50 \%$ of the last value of bid submitted $\left(b_{i}^{t-1}\right)$ to the new bidding value provided the user is not among the winners in the last bidding period in which the user participated. This is done in order to understand the effects of the price generation mechanism on the revenue of the auctioneer and it is summarised using this equation:

$$
b_{i}(\text { Price Unit })=b_{i}^{t}+\frac{b_{i}^{t-1}}{2}
$$

Figure 12 shows the revenue obtained by the WSP using the $50 \%$ price increases or the random price increases either with a discriminatory auction or uniform auction. From the results the discriminatory (50\% or random price increase) performs slightly worse than the uniform price (50\% or random price increase). It can be seen that the price increase per

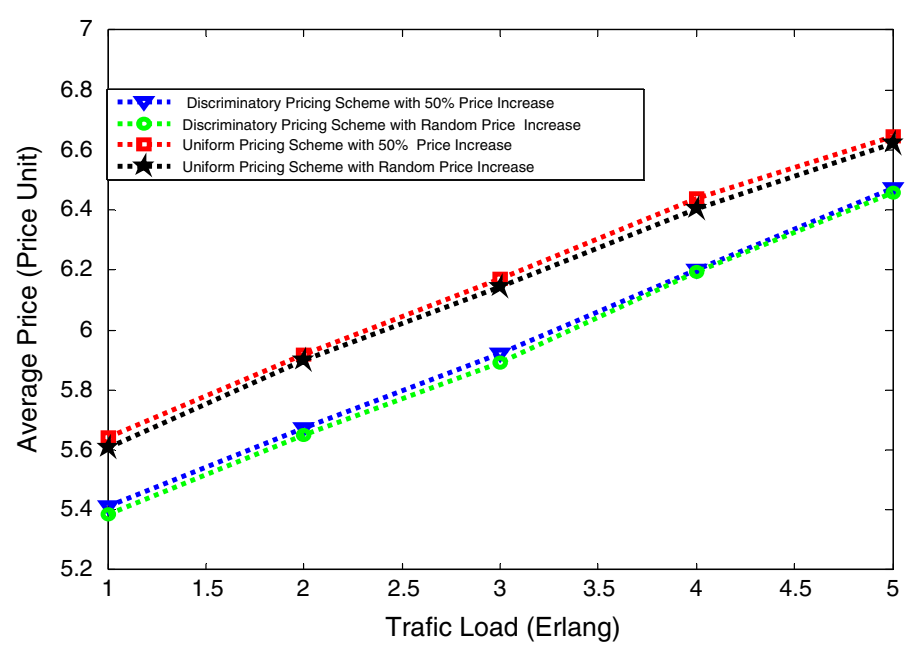

Fig. 12 Average revenue per file for different payment schemes 
session (50\% or random) does not have any significant difference in the result obtained for the revenue of the WSP. The reasons are explained better with Fig. 13.

However, from Fig. 13 the throughput of the system performs worse with the $50 \%$ price increase. This is because it $(50 \%)$ gives an advantage to the HPU to be able to win the auction process at the expense of the LPU thereby lowering the system performance. From the throughput result, it can be seen that the discriminatory or random price increase does not affect the throughput of the system. This is because the discriminatory or uniform price increase only has an effect on the average revenue of the service provider while the price increase per file (50\% or random) determines if the bid of the user is accepted or rejected and subsequently if the file is sent or not.

In order to determine the effects of the green payment and the reserve price on the performance of the system, the models with and without the green payment and reserve price are considered.

Figure 14 shows the traffic load against the throughput using the optimal value of $B$ for scenarios with and without the green payment and with the green payment but with and without a reserve price. The throughput results without the green payment are significantly lower because without the green payment the HPU is always interfering significantly with the LPU and other HPU in the other cells with whom they share the same channel, thereby making the system operate at a lower throughput. The schemes with the reserve price perform worse compared to the schemes without the reserve price because the reserve price sometimes hinders the transmission of users in the system. The hindrance is as a result of the users not being able to transmit when channels are available but they (channels) are not offered to the users because the offered bids are below the reserve price. However, the importance of the reserve price is demonstrated later with Fig. 17. The throughput also saturates close to 4 Erlangs per cell because 4 Erlangs is the maximum throughput per cell that can be achieved since 4 channels are available in each of the cells at the maximum.

Another important performance parameter is the energy consumed by the system. Figure 15 shows the energy consumption per file sent with and without the green payment and with and without the reserve price. The energy consumed increases with the traffic load because as the traffic load increases the collision in the system also increases. Furthermore, energy consumption increases with the traffic load. The increase in collision is

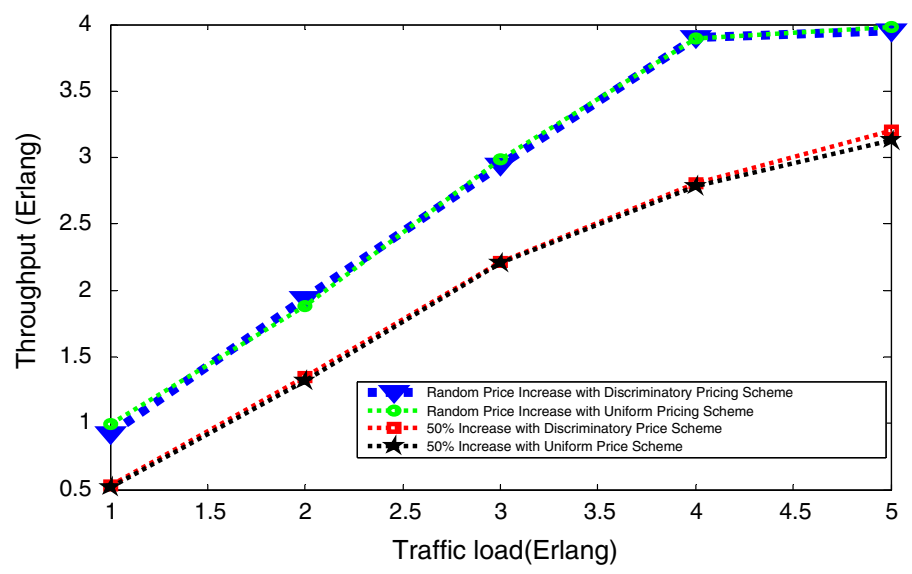

Fig. 13 Traffic load against throughput for different payment schemes 
because whenever a bid is rejected energy is wasted as explained with the energy model. The energy consumed using the green payment with a reserve price is slightly above the scenario without the reserve price. This is because a few of the bids are rejected as a result of the offered bid going below the reserve price. The difference is about $20 \%$ on the average, which is very low compared to over $120 \%$ average increase without the green payment. The energy consumed without the green payment is significantly more because more packets are being dropped as a result of HPU interfering and making the SNIR of the interfered signal fall below the SNIR threshold. This result also showed that the use of the reserve price increases the energy consumed by the system.

Figure 16 shows the traffic load against the delay. It can be seen that the delay increases with the traffic load for all the examined scenarios. However, without the green payment the delay is significantly more when compared with the scheme with the green payment. The scheme without the reserve price also performs better than the scheme with the reserve price. The reasons are the same as the reasons explained for the energy consumed in Fig. 15.

Figure 17 shows the average revenue with and without the green payment, with the green payment but without the reserve price and without both the green payment and reserve price. The price paid per file for all the scenarios increases with the traffic load because as the traffic load increases the competition in the system increases. From the bid equation, the bids also increase in order for the bids to be above the reserve price if there is a reserve price. The revenue increases with the traffic load with and without the green payment until when the traffic load is 4 Erlang and begins to flatten out because the maximum capacity of the system has been reached. The revenue without both the green payments and the reserve price is lower compared to all the others because the accepted bids are not necessarily above the reserve price. The crossover between the scenario with green payments and without a reserve price and with a reserve price is because at lower traffic loads the bids accepted without the reserve price is lower but as the traffic load increases, the green payments also increase thereby making the average revenue increase above the reserve price.

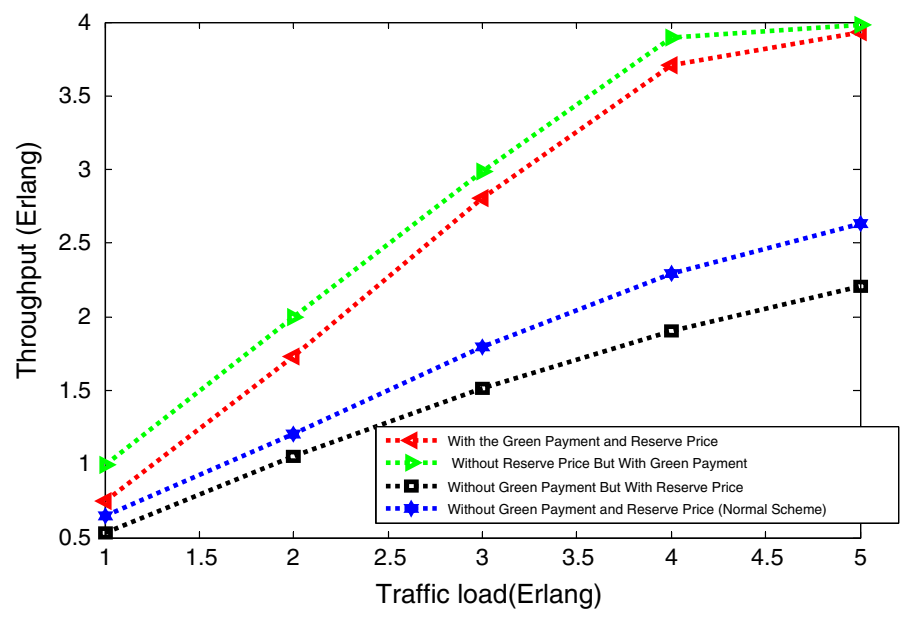

Fig. 14 Throughput per cell against traffic load for scenario with and without green payment and without reserve price 


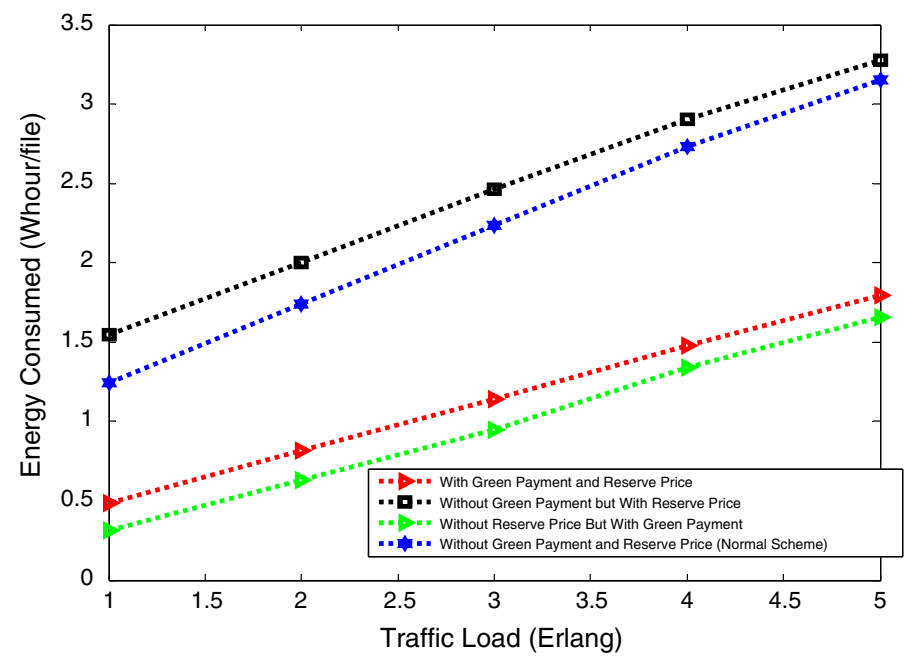

Fig. 15 Energy consumption against traffic load with and without green payment and without reserve price

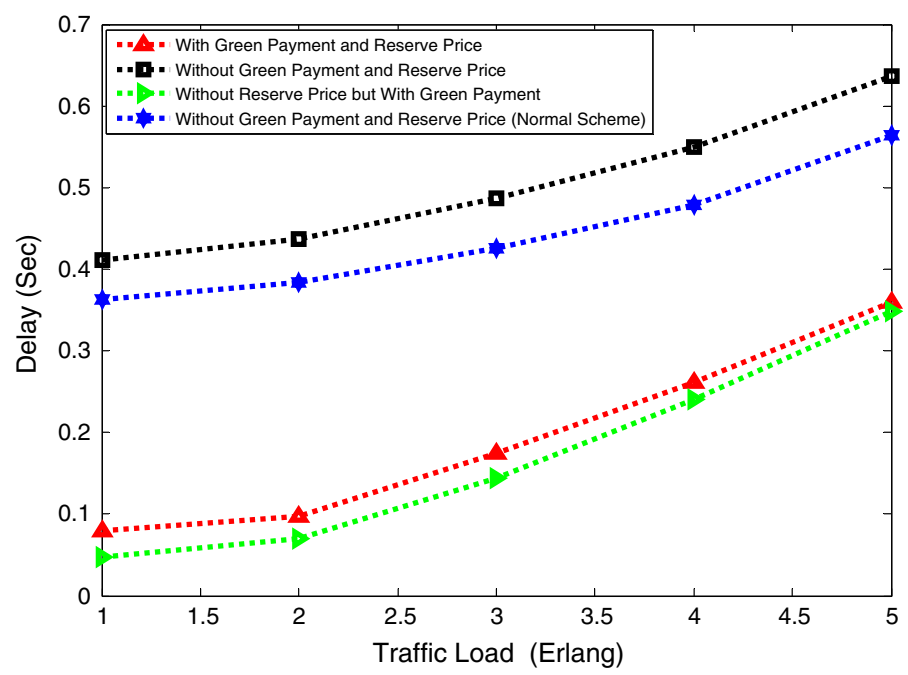

Fig. 16 Delay against throughput for scenario with and without green payment and without reserve price

The reserve price is useful at lower traffic loads because the users put in a bid, which is relative to the traffic load. At traffic load of 1 Erlang the slight difference between the two scenarios without the reserve price is because of the green payment.

Finally, in order to determine if the system can be self-sustaining the average and total green payment (tax and subsidy) is examined. Figure 18a shows the total subsidy and tax paid against the corresponding traffic load. The total subsidy paid increases with an increase in traffic load while the total tax decreases as the traffic load increases. The total tax decreases because as the traffic load increases fewer HPU are granted access to the spectrum thereby reducing the total amount of tax paid. It can also be seen from Eq. 22 that 


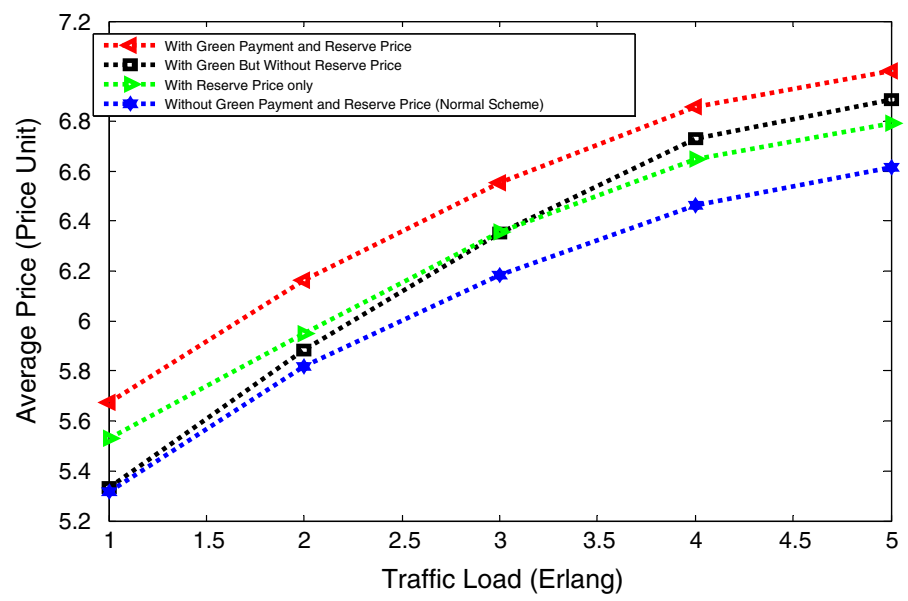

Fig. 17 Average price per packet sent against traffic load for scenario with and without green payment and without reserve price

as the number of arriving users $\left(N_{\mathrm{USA}}\right)$ increases (traffic load), the value of $j$ also increases meaning that more of the admitted users are falling below the SNR threshold (because the capacity of the system does not increase) hence, more subsidy is paid out and less users are paying a tax especially when case 1 as explained earlier occurs more often than case 2 or three. Case 1 is the situating where most of the arriving users $\left(N_{\mathrm{USA}}\right)$ arriving in the same period are LPU. It is worth pointing out that the occurrence of any of the three cases occurring depends on the user's arrival model explained earlier for all the traffic loads. However, as seen in Fig. 18b the average tax paid per successful transmitted file for each of the users is more than the average subsidy but the average tax per successful

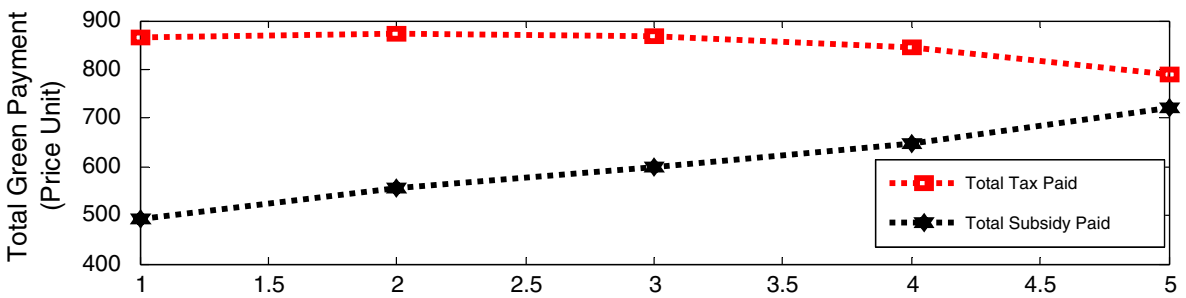

(a) Traffic Load (Erlang)

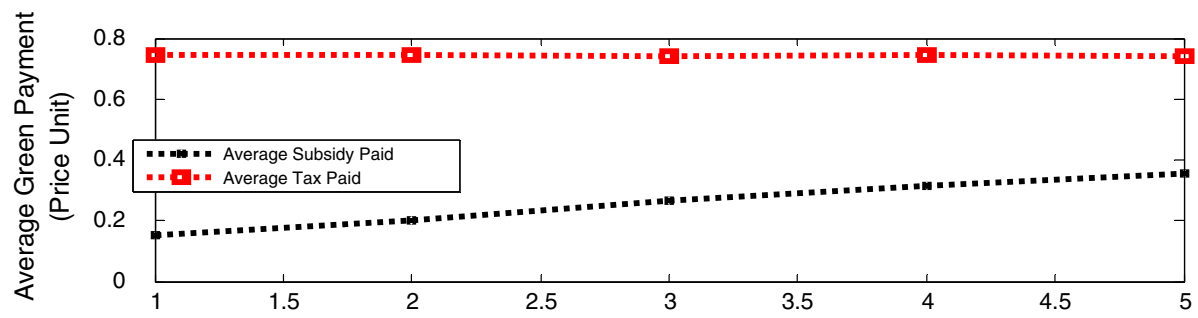

(b) Traffic Load(Erlang)

Fig. 18 Total tax and subsidy paid and average subsidy paid per packet sent 
transmission for the HPU is relatively flat. This is because the total value of the tax paid is decreasing with the number of HPU who are able to transmit successfully. This is unlike the LPU who are able to receive more subsidies and the average files transmitted successfully are slightly more. The tax paid decreases with traffic load also because none of the equations formulating the green payments increases with traffic loads (Eq. 21 depends on SNR not SNIR) but the number of HPU paying a tax or admitted into the system reduces with traffic load because more subsidy is paid out. The average subsidy however increases with the traffic load because more users are subsidised as the traffic load is increasing. It can be seen from the result that if the traffic load continues to increase or if a higher value of the green payment factor is used, a time would come when the total tax paid would not be able to finance the total subsidy.

\section{Conclusions}

An energy efficient dynamic pricing mechanism to assign the radio spectrum using a sealed bid auction process with a reserve price along with a green payment to help energy efficient users has been proposed. The green payment was derived from the inverse of Shannon's equation with some variables such as the green payment factor (ß) introduced. After examining the effect of varying $\beta$ on the ratio of successful transmission sessions of the HPU compared to the LPU in the system, the system throughput, the revenue of the WSP and the energy consumption in the system, the optimal value of the green payment factor (ß) is approximated to be 0.045 . This showed that the energy consumption level of the system can be varied with the green payment. This paper also examined the effect of the reserve price and the random channel assignment scheme and the assignment scheme with the least interfered channel on the throughput and discovered that both affects the system especially when the system is not fully loaded. Hence, it was discovered that there is a need to make sure that the reserve price is set to reflect the current traffic in the system and that the presence of the reserve price helps in increasing the revenue of the WSP at lower traffic load and that the green payment increases the gross revenue of the WSP. It also shows that discriminatory pricing scheme performs better than the uniform pricing scheme. This paper further showed that using the optimal value of $\beta$, the green payment scheme performs better than the scheme without the green payment in terms of increase in revenue, throughput delay and more importantly energy consumed.

Open Access This article is distributed under the terms of the Creative Commons Attribution 4.0 International License (http://creativecommons.org/licenses/by/4.0/), which permits unrestricted use, distribution, and reproduction in any medium, provided you give appropriate credit to the original author(s) and the source, provide a link to the Creative Commons license, and indicate if changes were made.

\section{References}

1. Staple, G., \& Werbach, K. (2004). The end of spectrum scarcity [spectrum allocation and utilization]. Spectrum IEEE, 41, 48-52.

2. Valenta, V., Marsalek, R., Baudoin, G., Villegas, M., Suarez, M., \& Robert, F. (2010). Survey on spectrum utilization in Europe: Measurements, analyses and observations. In Proceedings of the fifth international conference on cognitive radio oriented wireless networks and communications (CROWNCOM) 2010 (pp. 1-5). 
3. Lin, C., Iellamo, S., Coupechoux, M., \& Godlewski, P. (2010). An auction framework for spectrum allocation with interference constraint in cognitive radio networks. In Proceedings of IEEE INFOCOM, 2010 (pp. 1-9).

4. Subramanian, A. P., Al-Ayyoub, M., Gupta, H., Das, S. R., \& Buddhikot, M. M. (2008). Near-optimal dynamic spectrum allocation in cellular networks. In 3rd IEEE symposium on new frontiers in dynamic spectrum access networks 2008 (DySPAN 2008) (pp. 1-11).

5. Jinzhao, S., Jianfei, W., \& Wei, W. (2011). Dynamic spectrum allocation for heterogeneous cognitive radio networks from auction perspective. In 2011 Sixth international ICST conference on cognitive radio oriented wireless networks and communications (CROWNCOM), (pp. 176-180).

6. Lin, G., Jianwei, H., Ying-Ju, C., \& Biying, S. (2012). ContrAuction: An integrated contract and auction design for dynamic spectrum sharing. In 2012 46th Annual conference on information sciences and systems (CISS), (pp. 1-6).

7. Mölleryd, B. G., Markendahl, J., \& Mäkitalo, Ö. (2009). Analysis of operator options to reduce the impact of the revenue gap caused by flat rate mobile broadband subscriptions. In 8th Conference on telecommunication, media and internet tele-economics.

8. Sengupta, S., \& Chatterjee, M. (2009). An economic framework for dynamic spectrum access and service pricing. IEEE/ACM Transactions on Networking, 17, 1200-1213.

9. Sengupta, S., \& Chatterjee, M. (2008). Designing auction mechanisms for dynamic spectrum access. Mobile Networks and Applications, 13, 498-515.

10. Chun, S. H., \& La, R. J. (2013). Secondary spectrum trading: Auction-based framework for spectrum allocation and profit sharing. IEEE/ACM Transactions on Networking, 21, 176-189.

11. Aggarwal, G., Goel, A., \& Motwani, R. (2006) Truthful auctions for pricing search keywords. In Proceedings of the 7th ACM conference on electronic commerce (pp. 1-7).

12. Courcoubetis, C., Dramitinos, M. P., \& Stamoulis, G. D. (2001). An auction mechanism for bandwidth allocation over paths. In 17th International teletraffic congress (ITC) (pp. 1-11).

13. Jia, J., Zhang, Q., Zhang, Q., \& Liu, M. (2009). Revenue generation for truthful spectrum auction in dynamic spectrum access. In Proceedings of the tenth ACM international symposium on mobile ad hoc networking and computing (pp. 3-12).

14. Jain, T. (2006). Microeconomics and basic mathematics. New Delhi: FK Publications.

15. Moore, H. L. (1919). Empirical laws of demand and supply and the flexibility of prices. Political Science Quarterly, 34, 546-567.

16. Mitchell, P. (2011). Introduction to Communication systems [Lecture Note].

17. Feeney, L. M., \& Nilsson, M. (2001). Investigating the energy consumption of a wireless network interface in an ad hoc networking environment. In Proceedings of twentieth annual joint conference of the IEEE computer and communications societies (INFOCOM 2001) (Vol. 3, pp. 1548-1557).

18. Burr, A., Papadogiannis, A., \& Jiang, T. (2012). MIMO Truncated Shannon Bound for system level capacity evaluation of wireless networks. In IEEE Wireless communications and networking conference workshops (WCNCW) 2012, (pp. 268-272).

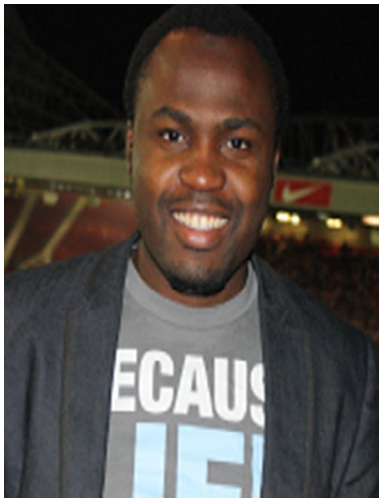

Abdulkarim Oloyede received his first degree in Electrical Engineering from Bayero University in Kano, Nigeria and M.Sc. degree in Telecommunications from The Department of Electronics Engineering, University of York in 2011. He completed his Ph.D. at the Departmnet of Electronics, University of York, UK with reserch focused on Spectrum Pricing for Cognitive Radio Networks. His research interest includes wireless communications network, green communications and cognitive radio. 


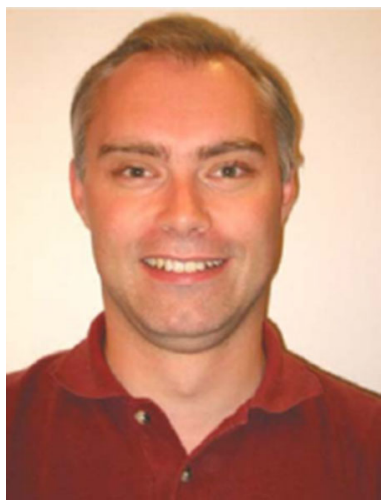

David Grace is Head of Communications and Signal Processing Research Group within the Department of Electronics at the University of York. He is also a Co-Director of the York-Zhejiang Lab on Cognitive Radio and Green Communications, and a Guest Professor at Zhejiang University. He received his Ph.D. from University of York in 1999, with the subject of his thesis being 'Distributed Dynamic Channel Assignment for the Wireless Environment'. Current research interests include cognitive green radio, particularly applying distributed artificial intelligence to resource and topology management to improve overall energy efficiency; architectures for beyond 4G wireless networks; dynamic spectrum access and interference management. $\mathrm{He}$ is a one of the lead investigators on FP7 ABSOLUTE which is dealing with extending LTE-A for emergency/temporary events through application of cognitive techniques, and recently a co-investigator of the FP7 BuNGee project dealing with broadband next generation access. He is an author of over 180 papers, and author/editor of 2 books. He currently chairs IEEE Technical Committee on Cognitive Networks and the Worldwide Universities Network Cognitive Communications Consortium (WUN CogCom), and is a member of COST IC0902. He is a founding member of the IEEE Committee on Green Communications and Computing. In 2000, he jointly founded SkyLARC Technologies Ltd, and was one of its directors. 